2017-09

Mental models: Exploring how people think about heat flows in the home

Goodhew, Julie

http://hdl.handle.net/10026.1/9561

10.1016/j.erss.2017.06.012

Energy Research and Social Science

Elsevier BV

All content in PEARL is protected by copyright law. Author manuscripts are made available in accordance with publisher policies. Please cite only the published version using the details provided on the item record or document. In the absence of an open licence (e.g. Creative Commons), permissions for further reuse of content should be sought from the publisher or author. 


\title{
Mental Models: Exploring how people think about heat flows in the
}

\section{home}

\author{
J. Goodhew ${ }^{1}$, S. Pahl'1, S. Goodhew², C. Boomsma ${ }^{1}$ \\ ${ }^{1}$ School of Psychology, Portland Square, Plymouth, PL4 8AA \\ ${ }^{2}$ School of Architecture, Design and Environment, Roland Levinsky Building, Drake Circus, Plymouth, PL4 8AA, UK
}

\section{Abstract}

To achieve energy efficiency targets, the behaviour of building occupants is critical in counteracting or enhancing efficiency measures. Yet behaviour and decisions are construed through the lens of the mental models that occupants hold. We used a mental models methodology to extend previous research in order to elicit occupants' $(\mathrm{N}=25)$ wider models around how they believe heat operates in their home. The research aim was to analyse the stories of heating, to reveal beliefs that occupants use when 'operating' their buildings. Twenty-five participants were asked to relate how they imagined (i) how their thermostat operated, (ii) how quickly their home heated up, (iii) where heat goes to when the heat source is switched off, (iv) how insulation works, (v) how heat flows around the home. We document the variety of mental models and specific features, e.g. how a high internal temperature can stem from a goal to feel warm fast, that when occupants use 'technical' vocabulary they may be imagining a different process from 'experts', how people use analogies such as wetsuits and weather patterns. We discuss the implications for energy efficiency. The stories of building users around how 
they operate their heating systems reveal assumptions that influence behaviour and can inform future communications.

Section/Category: Energy, consumption, and behaviour Keywords: Heat; Mental Models; Behaviour; Domestic Energy 
I Introduction

\section{1: Energy use and occupants}

Using energy efficiently is a key element in reaching EU targets for saving $20 \%$ of energy consumption by 2020 [1]. The behaviour of occupants and building users is a critical element because this can enhance or counteract the benefit of energy efficiency measures [2]. However, attempts to promote the energy efficient use of buildings are rarely based on an understanding of how occupants think and make decisions regarding energy use and energy efficiency in the home [3]. Every day actions in the home are underpinned by the "competences, skills, routines, attunements and working knowledge of the homes that are involved in the ....management of energy flows" [4, p155]. One way to approach these practices and underlying understanding is to explore the mental models that occupants draw on as they operate their buildings.

Mental models can make an important contribution to improving building literacy $[5,6]$ because they describe people's beliefs about a system, its elements and connections, which guide actions. As people strive to achieve warmth and comfort in their homes, everyday actions contribute to energy use (and efficiency). Occupants decide the temperature set point in the home, whether to insulate the loft, how long to keep the heating on, for example. All these considerations contribute to the efficiency with which energy is used in the home and can be conceptualised as being part of socio-cognitive mental models. Specifically, the research in this paper explores mental models in the context of space heating. Space heating is important as it, with water heating, 
accounts for approximately $80 \%$ of household energy use in domestic buildings [57].

1.2 Mental models, storytelling and the social construction of knowledge.

Mental models have been variously described as socio-cognitive representations of the outside world, as beliefs held by individuals or 'folk' theories held by people [7] as naïve physics or representations that people have of themselves and the things they interact with [8]. A mental models research approach is concerned with understanding human knowledge about the world [9] "through the careful examination" of the way people understand very specific domains of knowledge [9, p 1]. The mental models methodology involves asking participants to retell their stories or understandings, sometimes using a scenario to prompt the discussion. These domains of knowledge are typically complex physical and technical systems or devices. A mental model approach has been applied to the understanding of climate change [14] radon in homes [15], how liquids flow [16] and the understanding of the day/night cycle [18, see Boase et al. (in press) for an overview]. A particular example of how findings are applied to guide the development of risk communication literature can be found in Linville, Fischer \& Fischoff [19] who investigated the mental models of the transmission of the AIDS/HIV virus and used these findings to redesign public communications. Within the energy field, previous research has sought to capture and understand the mental models occupants hold of thermostat operation in the home $[10,53,54,55]$ the heating system [11] and electricity more generally [12].

Encouraging occupants to talk in detail about a specific domain of their knowledge and understanding is important to accessing a person's 
representations and their mental models. It is not uncommon for participants to use seemingly scientific terms but with an interpretation of that term which is quite different from the 'expert' interpretation. Without unravelling occupant understanding of these sorts of terms, experts and occupants appear to talk about the same topic, but at crossed purposes. An example illustrates this point. When asking occupants to 'tell me about radon gas in homes' occupants used the words 'radioactive' and 'gas' frequently, but their interpretation of these terms differed from how the expert would understand and use these words [7]. Similarly the communications in literature about radon gas in homes uses the word 'decay' to describe the depletion of radon over time. However, in the householders, this word evoked a mental model of radon emerging from decaying garbage in the ground [14, $p$ 98]. These 'miscommunications' can be discovered during in depth discussions with occupants where they can tell their version of their understanding, as they have learned about the issue in their own context, location and everyday life [20].

Indeed, in terms of domestic energy use, there have been multiple appeals for energy educators to use the processes and language of everyday life [20], arguing that energy use and energy conservation are affected by our tacit knowledge of energy. Tacit knowledge is socially constructed rather than learnt formally. Meaning emerges from the interplay between experiences, interpretation of the feedback and data in the environment. For example, Darby [23] evidences, in a study on energy transitions in a local Scottish community, how energy is used and understood differently, never the same in the same place, constructed through the experiences of social networks, the 
built environment, climate, geography and demographics. The retelling of past personal experiences in the home can also reveal phenomena in the private world of the home as a means of uncovering themes around energy, heating behaviour and the meaning of warmth $[7,25,56]$. For example, a study of the mental models of domestic energy consumption suggests that occupants are limited in how they think about and categorise domestic appliance consumption but may better understand energy usage in terms of practices rather than overall consumption [13]. This focus on occupants' personal experiences and lived behaviour, on meaning and constructed knowledge is important in order to understand how occupants think and make decisions that result in energy use, so that communication with occupants is on their terms.

Research into mental models has found that when individuals hold models of physical systems, these models tend to be stories or representations [7]. They are 'models' in that individuals use them to predict the outcomes of their actions and so guide behaviour. However, mental models are not the formal scientific models, concepts or theories characterised by abstraction, predictability and consistency. Mental models may change over time and are not necessarily real or correct; they can be fuzzy, incomplete, and conflicted [8]. However, a mental model can be seen as an abstract (folk) theory in that individuals may group mental models into analogies to refer and explain similar phenomena they encounter. An example of this is evidenced earlier in this paper when individuals applied their model of garbage decaying in the ground to explain radioactive decay [14, p 98]. 
In the domain of home energy and home heating use it is important to understand the prevailing mental models that people hold, as these can influence energy use and conservation. People interpret public communications through their mental models and so understanding these is vital to inform the design of such communications [e.g., 19]. Understanding mental models may go some way to explaining miscommunications or any unintended consequences of public appeals to conserve energy (designed by governments, climate change organisations or energy conservation agencies). For example, there is a reported gap $[21,22]$ between actual building performance and predicted energy use performance. Authors refer to occupants taking back the higher temperatures achieved by energy efficiency measures [4]. However, Janda and Topouzi [20] advocate for a learning story approach to understand this gap, in terms of 'a search for meaning in specific times and places, p. 520 (to complement the 'hero stories' where new (and heroic) building technologies will solve the energy demand problem as per the theoretical predictions of building simulations and models). They propose that learning stories can help in better understanding the moderating factors that affect energy use; the 'task complexity' and the real (and potentially 'messy') 'situational constraints' of the real built environment [20, p 529]. This paper presents the results of such learning stories by presenting people's representations and mental models around their in situ experience of heat flows in real situations. It contributes to a literature gap in this area. Previous research has provided some insight into mental models of heating systems but less on heat flows in the home.

1.3 Mental models of heating systems 
The literature on mental models around heating controls and occupant behaviour has documented different ways that people can think about the same phenomena. Early research by Kempton [10] found evidence that individuals hold one of two mental models when operating a household thermostat: the valve or the feedback model (or a partial model of these). The feedback model described a thermostat working by sensing the temperature in the home and switching the heating on and off to maintain the desired preset temperature. In the 'valve' model, people predicted that the thermostat operated by opening a flow of fuel: the higher the setting the more fuel released, so the warmer the home temperature. The latter is analogous with a gas burner on a domestic cooking hob, in that as the gas control is turned up, the gas flame increases in size and provides more heat [10, 8]. Norman [8] described a third mental model (the timer model) where individuals believe that the thermostat controls the time that the heating stays on, so if the thermostat is set to half way, then the heating is on for half of the time. Holding the valve model would lead individuals to predict that turning the thermostat up to its highest setting achieves the most heat. The traditional UK thermostat acts as a switch to activate the heating and then switches off once the temperature reaches the temperature set point in the home (most aligned to the feedback mental model). Further, the rate of heating is a constant, and the traditional UK thermostat does not usually control the speed at which the house heats up.

More recent studies have complemented these findings. The UK Energy Saving Trust [26] found that $32 \%$ of UK householders reported turning their thermostat up in order to heat the home more quickly, despite the fact that this 
action alone will not cause a space to heat more quickly. In the U.S., between 24 and $46 \%$ of participants believed that the home heated up more quickly when the thermostat was set to a higher set point [10]. In a study of Welsh participants, $62 \%$ also believed this to be true [27]. Additionally the EST also found that $38 \%$ of respondents felt it was more energy efficient to leave their heating on low constantly, despite general advice to switch off heating when not needed. They believed that turning the heating off and then on again would use more energy in the task of reheating the colder building [26]. Indeed, Jones, Fuertes, Boomsma and Pahl [28] found that thermostat settings varied across households and that occupants who agreed more strongly with the statement 'I don't understand how my home uses energy' also reported higher thermostat settings. Further, people's perceptions of energy consumption tend to be out of line with calculated energy savings [29, 30] specifically, people often underestimate the potential of energy saving actions such as turning down a thermostat. Social tenants, as an example, were not making use of the controls that their heating system offered such as the Thermostatic Radiator Valves (TRV's) [31]. Indeed, when a study asked 180 people to draw 'what energy looks like', the sketches revealed ideas about energy that were at odds with the words and numbers (kilowatt hours for example) that are often used by professionals in the building/energy sector to describe and conceptualise energy [32]. Instead of technical references, drawings expressed the idea of energy being 'magic', energy being everywhere, and drawn elements often related to natural imagery (sun, waves, wind and lightning) but also to infrastructure (pylons). In addition, Revell \& Stanton's [6] study showed that people can hold distinct and incongruent 
models of their heating system. A group of six overseas postgraduates, living in the UK, had incomplete representations of the heating system and bypassed using the thermostat device altogether. Revell and Stanton's study specifically considered the heating system in buildings, rather than the way heat behaves in the home. The evidence shows that overall, people in general, can have a very varied understanding of energy and of a domestic heating system [33] and at least some of those models will differ from the way the system or device actually works.

This is not to say however, that mental models of heat can or should necessarily be categorised in to those which are 'correct or incorrect', or even in agreement with technical explanations or the 'expert' viewpoint on heating. Occupants operate a heating system but construct their own meaning as to how it works, and how it works for energy efficiency, out of their experience with the system, their practical understanding, their habits and 'know-how' [34, 35]. Therefore, to regard the operation of a heating system in the home as purely a technical task seriously undervalues the influence of the user. The purpose of gathering mental models is to build a better understanding of the decisions and behaviours that influence energy use, the human and situational moderating factors that affect energy use via the operation of heating in the home, which can then be used to design better systems and interfaces. Stated otherwise, to add to our knowledge of the situations under which energy is used research should not focus on whether mental models are 'right' or 'wrong' in the technical sense but identify the models and study these ways of thinking. Even if they are matched to an 'expert' model and appear technically 'right or 'wrong', mental models are not technical models. 
As already explained, occupants can seemingly use technical vocabulary but be thinking about that process in a different way $[7,14]$. Mental models can be simplifications and distortions of apparently technical models and equally can afford behavioural energy efficiency advantages or inefficiencies whether 'right' or 'wrong' [10, p78]. In sum, a focus on the mental models of heat, specifically, can enhance our understanding of the human element in this socio-technical system.

\subsection{Mental models of heat}

The research studies included in section 1.3 above have focussed on the operation of heating systems (e.g. thermostats and TRV's). However, we argue that behaviour related to these controls do not occur in isolation and may well be influenced by wider mental models about heat, how to get the home warm quickly and how the house stays warm. For example, if individuals believe that it takes more energy to heat the home from cold (than is saved by turning the heating off/ down) they may choose to keep the heating on and avoid changing the thermostat setting at all [36, 11]. Similarly, energy use behaviour may be influenced by how one thinks of a space warming up, so an occupant might believe that their home warms up faster if he or she sets the thermostat set point temporarily higher than normal [10]. In this way, energy use is influenced by mental models about heating, the model of how people think their home heats up, and how heat behaves in the home. This is an important gap that our research seeks to address.

There is little in the energy efficiency literature that describes the layperson's mental models about heat. There is literature about models that students hold 
in terms of theories about heat but this is in the context of their education as undergraduate physics students $[37,38]$ and not the mental models of heat in their homes. However, it is relevant to summarise some of this literature here since the findings inform our understanding of the variety of mental models of heat. Four mental models of heat were identified. One model was of heat as particle motion with a transfer of thermal energy due to a temperature difference (temperature being the measure of the average thermal energy in the substance and temperature is a scale of the kinetic energy of the molecules [39]. Students also thought of heat as an intrinsic property of a substance [38] as contained in an object [37] or as a material substance which can be transferred from a hot object to a cold object and vice versa. To summarise, these mental models suggest that heat can be thought of as a process or as a material substance $[40,41]$. These findings, albeit with physics students, demonstrate the range of mental models held by individuals about the same phenomena of heat and heat transfer. These studies also provide evidence to suggest that mental models are persistent and resistant to change even after formal schooling: Australian, American and Korean school and university leavers still favoured the mental models they held prior to studying the subject; these were unchanged after formal education and preexisting models coexisted alongside the learned scientific models $[42,43,44]$.

That mental models are resistant to change is an interesting finding and may seem puzzling, but Morgan et al. [7] found that people do not necessarily infer errors in their mental models when presented with factual statements which contradict their models. It is possible that people see no reason to change or review a particular model if employing it successfully achieves their required 
goal. Similarly, mental models will be retained if there is no feedback to challenge that way of thinking. So for energy efficiency, giving occupants information about energy efficient behaviour alone may not be enough to change behaviour where their mental models around heat already achieve their goals.

\subsection{The present research}

Our study builds on previous research on the mental model of heat systems but extends this approach to include the wider stories and models of how people believe heat operates in the home. We include a scenario to elicit mental models and test a relatively large group of people for qualitative/mixed-methods research. Two research questions guided our approach. Firstly what are the prevailing mental models of UK occupants around thermostat use in homes amongst a larger group of participants? Secondly, what are the prevailing mental models around heat and how heat behaves in a building? The study used semi structured interviews and the mental model interview methodology described by Gentner, 1983 [9] and Morgan, Fischhoff, Bostrom and Atman, 2002 see Chap 4 [7]. We asked participants to explain how heating devices and systems worked in relation to how participants used them [8], to discuss a scenario related to home heating in their own home.

This methodology enabled participants to access their own stories of the way their homes use heat and the behaviour of heat. We varied the methodology by asking participants to sketch their ideas if possible [32]. Finally, we specifically captured any analogies that participants used in their response. 
2 Method

\subsection{Participants}

The study draws on data from 25 participants (9 males, 16 females). All were resident in the UK but twenty three of the participants were UK citizens, one participant was German (participant number 22) and one participant was from Africa but had lived in the UK for some time (participant number 21). Participants were recruited via the Plymouth University research participant pool. This pool includes members of the general public, students and university employees who have volunteered to assist in the University's research programme for payment. Recruitment to studies takes the form of an e-mail invitation to the pool with very brief details of the study. Participants who signed up for this study were undergraduate students $(n=8)$, postgraduate students $(n=3)$, retired $(n=4)$, University employees $(n=1)$ or other members of the general public $(n=9)$. Age of the participants ranged from 25 to 71 years. They received a payment of $£ 8$ in return for taking part in a 60 minute semi structured interview on the topic of 'Heat Use in Your Home'. In order to participate, interviewees needed to be paying their own energy bills and be over the age of 25. Participants were briefed that the aim of the research was to understand people's ideas about energy use in the home and that they would be asked a series of questions about their use of energy (gas and electricity). We also explained that we did not require technically accurate answers; rather we were interested in hearing how they imagined heat and heating systems working, not in what they thought were the facts. Twenty-two participants had a UK traditional gas fired wet central heating system or Hydronic Heating System in their homes, with a boiler, thermostat 
and radiators. Participant 4 had no central heating and relied on portable electric convection heaters for warmth. Participant 5 described a more modern heating system installed in 2007. Participant 18 had an oil fired heating system. See Appendices 1 for examples of how participants explained their heating system, referring to controls and buttons, timers and habitual ways of adjusting the heating.

\subsection{Procedure for Data Collection and Materials}

Following Morgan et al. [7]), we elicited mental models using an open ended, conversational interview procedure with individuals. Questions and a scenario were devised in consultation with engineering and building experts.

Interviews took 45 - 60 minutes and were structured into three parts. Participants responded in a free and unconstrained manner without any time constraints per question. Part One involved setting the tone and the topic and lasted approx. 10 minutes. The participant was first asked to describe his or her own actions in a general manner: "Tell me what you (typically) do if you feel cold in your home? Can you tell me more about this? What I would like you to do now is just to talk to me about whether you can change how much energy you use."

Part Two became more focussed on the understanding of heat and took approx. 25 minutes. This section was intended to explore the mental models of heat in terms of heat exchange, heat storage, and transmission.

Participants were asked: 'Can you tell me what you understand about the heat in your home and what happens to it after it is generated by the source of heat 
(i.e. fire/boiler)? What can you tell me about the way you imagine heat moving around your home?'

In Part Three (duration approx. 25 minutes) the interviewees' understanding of heat was tested by prompting stories of how they used their heating systems. Participants were asked to explain how heating devices and systems worked in relation to how they used them [8], to solve a series of small problems and to discuss a scenario related to how they imagined:

i). the thermostat operating.

ii). how quickly their home heated up.

iii). where heat goes to when the heat source is switched off.

iv). how insulation works.

v). the heat flows around a home.

Participants were provided with a variety of questions in the home, such as (1) how they warmed the home when they needed to be warm quickly, (2) where heat in the home went to once the source of heat was switched off. A scenario asked 'On a cold day when you get home and the house is cold, should you turn the heating up extra high to warm the building more quickly or not?' The specific questions are summarised in Table 1 along with a rationale for each question.

The interviews were audio recorded and later transcribed verbatim. Transcripts were read and inputted to NVivo 11 software. First level coding involved obtaining the frequency of each type of response. Participants' responses were grouped according to each of the five interview questions/topics of heat. So for example, the scenario responses favouring 
turning the thermostat up higher to achieve faster warmth were grouped together and counted.

For second level coding responses were grouped into similar categories and analysed. Patterns and similarities in the content of the stories were identified and models drawn from the data. Below, participant quotes illustrate key findings.

$<$ Table 1 about here $>$

3 Results and Discussion

\subsection{Results}

Categories of mental models of heat are described for each of the five areas of heating identified earlier in this section (see Table 1 for an overview and Section 2.2):

3.2). Mental models of thermostat operation

3.3) Mental models of how quickly a home heats up (rate of heating)

3.4) Mental models of where heat goes to when the heat source is switched off.

3.5) Mental models of insulation

3.6). Mental models of heat movement.

3.2 Mental models of thermostat operation

The stories that participants told about the thermostat operation were divided into three mental models; two models (the feedback model and the valve 
model) were identifiable clearly from participant responses to questions. However many responses did not contain a clear picture of how the thermostat operated and we called these responses 'fuzzy models'. A feedback model $(n=12)$ was described by the largest number of participants. In other words, they described the thermostat switching the heating on or off at pre-set temperatures in order to maintain an approximate temperature in the home (Table 2). It was clear that these participants described the thermostats like a switch turning the boiler on in the way that the boiler 'cuts out when it reaches' the desired temperature setting. In contrast a smaller number of participants $(n=4)$ described a model in which the thermostat worked like a valve in that, as the thermostat was turned up, an increased flow of fuel would be burned or "more gas would be used up" or "more gas comes out' (Table 2 for full exemplar responses) with the thermostat controlling 'how hard the boiler is working' rather than how long it is working. The 'fuzzy' models $(n=9)$ in contrast was the category for those responses where participants seemed to find it hard to communicate the operation of the thermostat "a radiator is filled with water right? So when you turn the thermostat up I guess it heats the water in the radiator to that temperature" or "if it (the thermostat) is set on a timer it would not switch off, it would maintain". Participants also clearly expressed their uncertainty in the way it operates "Interviewer: Do you know how it works, Participant 13: No, I don't know" and "I've never really thought of it, it does what it says on the tin" (Table 2).

There was evidence of an analogy with another domestic appliance here. Participants mentioned the flame on the cooker hob to explain how the boiler flame operated in response to the thermostat. They described the amount of 
gas increasing or decreasing in response to the thermostat being turned up or down, in the same way that they observed the gas flame become bigger or smaller in relation to their turning the control on the cooker hob. The participants reported that "it's [the thermostat] a bit like a cooker you turn it up the more gas sort of comes out". This indicates how the operation and visible use of one appliance is used to explain how another domestic appliance operates. It also suggests that domestic appliances may not been seen in isolation in terms of how they operate.

\section{$<<$ Table 2 about here $>>$}

3.3 Mental models of how quickly a home heats up (Rate of Heating)

Asking participants to connect the thermostat operation to how quickly their home would warm up revealed more about how the participant used the thermostat and the models around this behaviour. When participants were asked whether they would turn up the thermostat set point in order to get the house warmer faster, there were four prominent models about the rate at which a home becomes warm. (Table 3). The 'constant heat rate model' was held by the largest number of participants $(n=11)$. In this model participants imagined that increasing the thermostat set point would be an ineffective strategy for getting the house warmer faster. These participants describe how heat rises gradually through the temperature range at a constant rate (see Table 3 for participants' quotes) and therefore turning the temperature set point up would not achieve a warmer home more quickly. Instead it would only lead to a temperature overshoot or "get it [the home] to a hotter temperature" (Table 3). Indeed Participant 5 stressed that, given this constant 
rate of heat, s/he will adjust behaviour to get warmer faster: "I will wait and I will put on a cardigan".

The second model $(n=9)$ was the 'higher temperature, warmer faster model'. This mental model predicted that turning the thermostat up would lead to the house warming up faster.

One participant $(n=1)$ felt that turning up the temperature setting was something that they would do but that this might achieve a psychological rather than a 'real' benefit (Table 3). In other words it was the feeling that they were pushing or requesting the heating to work faster.

There was a fourth mental model evident in this sample; the 'slowly slowly' model of how a home gets warm $(n=1)$ as described by one participant (Table 3). This model predicted that if the heat is slowly acquired, then it will "warm up slower but you will have that heat for longer" as it will stay longer in the surroundings. This participant was the only participant to use portable electric convection heaters for warmth in her home. Her mental model of heat seemed to relate to the experience with appliances; portable heaters which 'cut out' when they reach a set temperature and cut back in when the environmental temperature drops. Her experience was that the house quickly felt undesirably cold when the portable heaters cut out, therefore she preferred a constant lower heat than the on-off, cold to hot rotation:

"With the fires that we have got. When you do put it on high it goes off more often so it cuts itself out. And when you have it on lower it stays at that temperature consistently whereas when you put it on high it would stay on for a few minutes and then it would go cold again and 
then it would keep going on and off like that and you think, oh I feel cold, when you have it on 15 or 20 its going to stay at that heat and not keep switching itself on and off."

The analogies with other appliances described in section 3.3 and 3.2 shows a socially constructed approach [24] to the development of models of heat; with participants learning about heat from their interaction with the environment and specific domestic appliances.

$<<$ Table 3 about here $>>$

3.4 Mental models of where heat goes to when the heat source is switched off.

Participants were asked what they imagined happened to heat when the heat source was switched off. Responses to this question contained conflicting ideas about heat and therefore, we present the range of responses direct from the interviews but we do not force a mental model categorisation.

Often the participants were surprised by this question, some explaining that they had never thought of this or that heat behaviour and 'heat loss' was a 'mystery' (see Appendix 2 for fuller exemplar quotes). Many participants reported that they had 'no clue' or 'don't know' an answer to this question.

The most common response referred to heat 'escaping' or 'evaporating' $(n=6)$ through cracks in the walls, or through doors and windows as they are opened. In the responses below, P2 and P16, whilst using the term 'evaporate' to describe the heat loss, seem to be describing convection. The Oxford English Dictionary describes evaporation as "the process of something abstract ceasing to exist". Convection on the other hand is "the movement caused 
within a fluid by the tendency of hotter and therefore less dense material to rise, and colder, denser material to sink under the influence of gravity, which consequently results in transfer of heat".

P2: "I never really thought about it, it just sort of seems to, like if I open a window and it just sort of escapes. Other than that I would not know, it sort of like evaporates".

Participant 16 seems to describe a type of heat transfer but uses the term 'evaporate':

P16: "I don't know, it just gets evaporated into the air I suppose.

I: How do you imagine that happening? So you said evaporated into the air.

P16: I don't know, I suppose when you open a door the sort of heat goes out I don't know".

Participant 17 describes a convection process to describe where heat goes to:

P17: "I suppose heat...well obviously it rises and you're going to lose some of that through the floorboards to the upstairs flat. I've lived in upstairs flats and it's always warmer than being on the ground floor because you get the heating from downstairs, sometimes it's too much. But obviously windows, we've got double glazing but it's old and some of the windows don't quite shut properly I think that's going to use heat of course, under doors. Yeah I suppose that's enough dissipation of it over time, say an hour, you know I think it probably... most of the benefit is lost over that sort of time frame I suppose". 
Participants also referred to heat escaping through the walls of the building. This response is not an unexpected finding therefore, however, our responses indicate a more complex picture, with participants understanding that heat is lost through walls, in terms of the cracks in the walls, yet were also bemused that walls with all of their layers of bricks, blocks, plaster and paint, are anything but solid.

P19: "I always assumed stones are solid ---- and nothing can get -through them. Um, but that, yeah, so I think about maybe like it goes through like cracks and stuff."

\section{I: And then what?}

P19: a little bit filtering out - like through those sorts of things in that crevices and stuff. Um, but yeah, still I -- I find it really hard to imagine air being able to go through walls -- because you just see them as set solid things and then only like painted like these (points to the painted walls in the room)-- a big block. Um, but if you look at quite a lot of buildings, they build them like of breeze blocks and stuff, there is quite a lot of air in them. So it does make sense that they can go through".

P4: "I suppose it's trying to get out of the windows and the emm any cracks anywhere. Yes, so I imagine it's just stagnant in the room until it can find ways out really. Then the cold air will come back in again. Yeh, so, but, I think because I tend to feel the heat, I just imagine it stuck in the room really, rather than just escaping. Like we have got it all quite secure and that with double glazing." 
However, as participant 4 above describes, whilst heat is seen as escaping, at the same time, it is viewed as stagnant, not moving. Participant 20 also imagined heat as stagnant, a potential of the boiler, locked in the boiler, ready to be released.

I: "So the moment you switch the whole thing off, where does the heat disappear to?

P20: I got no clue, I view is as it locked up in the boiler. Ha-ha, I know it's completely not how it is at all but I just view it as locked in this little box that is the boiler.

P20: And then it sends signals to everywhere else to turn it on so I just view that as the potential for the heating..... I have not got a clue. Not got a clue, other than I see the device that I press."

\subsection{Mental models of insulation}

Naturally, thinking about where heat goes to raised the question of insulation and its effect on where heat goes. We asked participants how they imagined insulation working and what difference insulation would make. Two participants described the properties of good or bad conductors (Table 4) such that it would 'hold' or 'stop' the heat, "that would not transfer the heat so readily." Participants also provided a model where insulation worked by 'bouncing (heat) off the insulated walls and 'bouncing (heat) back off the windows' and back into the house. This was how participants imagined the efficacy of upgraded insulation. The notion of 'solidity' also appeared here. Participants were conflicted in that they thought insulation would help but they found it difficult to imagine heat 'going through solid walls' (Table 4), whereas windows were thinner and so the model of 
heat loss through windows made sense but was related to the thickness of the material.

Again, we observed that participants used analogies to explain the behaviour of heat. Participants used the analogy of insulation as clothing and how it keeps a human body warm and how a wetsuit works to insulate the body.

$$
<<\text { Table } 4 \text { about here }>>
$$

3.6 Mental models of heat movement.

When we asked our participants to describe how heat moved, respondents consistently described heat "rising" or as a particle movement. They drew on analogies such as those from biology (particle movement was described as “microbes whizzing around" by participant 3) and from geography such as wind and weather patterns (Table 5):

P14: "I suppose maybe it's like the whole...sort of like rain system, you know sort of hot air rises, cools down, turns into rain, comes straight down again because it's cold".

Participant 3 specifically referred to weather patterns and geography class to explain their model of heat moving in the home:

P3: "Geography days, offshore drift. Air goes up and sea comes up, offshore breeze in the morning, night comes the other way".

However, when we asked participants to describe how heat moved in relation to how they used it, by asking them how they became warm, their responses were more varied. In addition, asking participants to draw their explanation revealed 
variability in their views. Whilst heat rising, was a familiar model (Fig 1), some described heat as spreading (see Fig 2) via waves of heat or visualised as speech bubbles coming out from a heat source such as a radiator.

$<<$ Fig 1 and 2 about here $>>$

$<<$ Table 5 about here >>

\section{General Discussion}

This research investigated how occupants imagined heat and heating in the home in order to identify and document the variety of mental models held. Building on Kempton's [10] and similar more recent research into the mental models that occupants use to think about thermostat operation, we extended these findings by eliciting wider stories and models of how people believe heat operates in the home and by using a larger cohort of participants $(\mathrm{N}=25)$. Using semi structured interviews, and relevant household scenarios, participants provided us with their stories and models of how they imagined heat working in relation to their everyday lives.

\section{1: Mental Models of Heat}

\subsubsection{Models of thermostat operation}

Our findings confirmed that there are varied mental models that people hold around working a thermostat and heating the home, in line with previous research [5, 6]. In our cohort, a similar percentage of participants held the valve model of thermostat operation as observed by Kempton in 1986 [10]. This striking finding is that across two countries (US and UK) and in an almost 30 year gap, mental models about this particular device and how it works have changed very little. In other words, people 
use their heating systems on a daily basis, yet their interaction with the system does not lead them to a standard understanding of how it works, nor have we found any evidence that potential technical advances or societal discourse around saving energy have changed conceptualisations in people's minds. Given the speed of change in other technical domains within the same timeframe and people's rapid adaptation - let's take smartphones as an example - this is certainly noteworthy and indicates how disconnected most people are from the domestic heating systems. In our study $36 \%$ of participants held a higher temperature - warmer faster model and told us they believed that turning the thermostat up would lead to the house getting hotter more quickly. This finding is in line with other studies $[26,10,27]$ and has an impact on energy efficiency as setting the thermostat to a higher than desired set point will achieve increased energy use and possibly lead to purge actions to reduce the heat in the building (or to accepting this higher temperature/'take back') [4]. Therefore some overshooting of temperature in homes may not be due to a desired higher indoor temperature, but a desire to get warmer quickly. Indeed these mental models might be applied to operate new home heating technologies and control mechanisms e.g., the smartphone example above.

Holding a 'higher temperature - warmer faster' model and also holding a valve mental model of thermostat operation could lead to an occupant being more reliant on the heating system to feel warm. In contrast, having a feedback model of thermostat operation and/or a constant rate of heat model (and believing that turning the thermostat up higher does not achieve faster warmth) could lead an occupant to conclude that to feel warmer faster they have to employ adaptation behaviours, such as putting on another layer of clothing. Indeed they may put an extra layer of clothing on sooner. 


\subsubsection{Models of Heat}

We asked participants to imagine where heat goes to when the heat source is switched off and to describe the difference that insulation makes. These responses were difficult to categorise into a distinct set of models. Participants described principles of heat movement with technical vocabulary (evaporates vs convection for example) but with differing meanings. The conclusion here is that when using this vocabulary of heat, occupants may be using the same words but imagining quite different processes, so 'experts' and laypeople may be seemingly talking about the same issue but at crossed purposes [7].

The walls of buildings were viewed as having gaps and cracks where heat was 'lost', yet walls were also believed to be solid and impenetrable. Insulation, another wellknown word, was understood to work differently by different occupants. Like the undergraduate students in $[37,38,39]$, our participants described insulation working in very different models than a heat transfer model for example, heat was imagined as 'bouncing' off the insulation and back in to the room.

One observation is that models of heat movement relate to the decisions which underpin efficiency action such as the installation of insulation. How one imagines heat escaping through walls or whether one imagines walls as solid and impenetrable might not be technically 'right' or 'wrong' but might affect one's decision to install wall insulation. Similarly, thinking of draughts as a cold air convection current might aid the understanding of and raise the importance of draught proofing. Further, holding one model of insulation may make it difficult to 'see' an alternative model and this will affect how an occupant interprets energy efficiency information.

However, the responses presented in this paper reflect strongly that the behaviour of heat is something of a mystery to some, with participants repeatedly telling us that 
they "had no clue". Whilst occupants experience warmth, they do not easily experience or see conduction or convection of heat, nor the operation of insulation (albeit they can feel the difference). With modern central heating systems, where the system works to maintain a set desired temperature, occupants experience warmth without knowing how much that system is working (harder) to combat heat loss through the walls or draughts in the building.

\subsubsection{Analogies}

Participants drew on several analogies to explain how heat worked, drawing on mental models already formed in one setting, to apply to other scenarios. Some participants referred to a geography analogy to describe heat movement (onshore and offshore breeze) and not a model specific to buildings. Some mentioned other appliances in the home and how they observed them working to explain the operation of a second domestic appliance (so a gas flame on the cooker hob was seen as analogous with the flame in the central heating boiler). The experience of portable electric heaters informed a model of how heat behaved. Insulation was seen as analogous with how a wetsuit worked or how clothing worked to keep a human body warm. Analogies are used to communicate and to clarify a point, and their use suggests that participants found the analogies more available and easier to use in explaining their point about heat in homes. This speaks of our relationship with heat and with buildings, which in turn suggests that explaining heat movement in terms of buildings is less easy. This observation fits with previous research which suggests a limited taxonomy around energy use in the home [13]. Using analogies to communicate with householders has great potential for improving understanding.

4.2 The social and experiential construction of knowledge and action. 
Taken together, the responses to our interviews support the social and experiential construction of knowledge of heat and heating systems [24]. Knowledge emerges from the experience of heat, social experiences, interaction with the heating system and formal learning. The experience with the built environment is a critical element in the process of constructing stories and models of heat, a place of learning in itself $[46,56]$. There is scope for building users to play a more active involvement in building performance, observing that buildings provide feedback to their users and users are differentially equipped to interpret that feedback.

Further, our findings generally support Royston [4] and Revell et al.'s [6] argument that systems in the home could be designed better to support 'knowing how' to operate the system for energy efficiency. It appears that some occupants can successfully achieve warmth and heat in the home, whilst their model of heat in the home is unclear. They may not, however, necessarily achieve warmth in the most energy efficient manner. One traditional way of encouraging energy efficiency is for occupants to learn about the efficient use of heat in the home system; another way is to build feedback into the home environment so that the heating system communicates its energy efficient operation However, at present few building systems provide feedback that easily and intuitively promotes learning and efficient action. For example, feedback could be given at the interface of heating appliance and system use to communicate heating progress (in fact some new thermostats do have a screen which shows the desired temperature and the current temperature status in the house). Whilst the temperature is reaching the desired set point, a progress bar animation might be visible to provide feedback that the system is working towards the goal temperature. This communicates the rate at which the home is warming up. 
Overall, we set out to listen to building users' stories in a mental models approach, looking at the representations and meaning that occupants connected with the system in their own home. We present a picture of heat use as a distinctly sociotechnical system, where mental models of heat can be conflicted and messy ideas abound about heat, building fabric and energy efficiency. Authors have suggested that environmental education programmes should contain an element that teaches about building literacy [46]. Janda [46] and Janda and Topouzi [20] push for researchers and policy makers to acknowledge the socio-technical nature of the built environment. This is in line with wider calls for an interdisciplinary, systems-based approach that truly builds on the science of people in order to address the societal challenges of today, be they related to energy specifically or to broader issues such as climate change $[47,48]$. Our findings support the argument that, rather than focus solely on technical fixes to achieve energy demand reduction, we should harness and build on the users' capacities and capabilities.

\subsection{Future Work}

Firstly, it would be of interest to apply the mental models methodology to explore other aspects of behaviour in the home, such as how householders approach behaviours that impact on energy efficiency such as ventilating the home, dealing with condensation, awareness of the relationship between indoor temperature and heating bills, or the impact of thermal mass vs thermal insulation. Further research could explore how models interrelate. The approach would also lend itself to exploring the perceived link between the home (fabric and behaviour) and both comfort [25] and health outcomes. Moreover, we do not know yet to what extent these models influence the perceived efficacy of energy efficiency actions such as insulation. Secondly, future research should test the prevalence of these models 
over a larger, ideally representative sample. A mental models approach takes these initial models and adopts a survey approach, adapting the questions to assess widely held models across the general population [7]. Future mental models work in this area should also integrate the elements that were our focus into a more comprehensive, linked model to represent notions of causality better, for example whether holding a certain model leads to certain heat related behaviours $[7,52]$. The approach should also be followed through to the development and testing of purpose-designed public energy efficiency communications, as this last step of the process has been neglected in mental models research to date [18]. Thirdly, the link to action should be investigated, for example do they affect the willingness to install energy efficiency measures? Finally and importantly, there is scope to research how mental models of heating and buildings can be changed through the provision of effective energy feedback. This is likely to be different from feedback about energy (energy literacy). Feedback could include visualisations of heating processes or the effect of behaviour on heating. The eViz project has, for example, investigated the effect of occupants seeing thermal images which show the usually invisible and difficult to imagine effect of draughts and missing insulation and has assessed the effect of this feedback on occupant behaviour [50, 48, and 51]. This research could be extended to study the effect such visualisation has on occupant's mental models of heat and the role of visual images in the process of constructing knowledge of heat and heating behaviour.

\subsection{Conclusion}

In conclusion, we extended earlier research findings on the mental models of heating systems to elicit wider stories and models of how people believe heat operates in the home. Listening to and analysing the stories and representations of occupants 
around how they operate buildings and their own heating systems is important. These stories reveal underlying assumptions that can influence behaviour and energy efficiency. For example, setting a high internal temperature on the thermostat can stem from the belief that this is how to feel warm fast. Further, whilst occupants use technical terminology such as convection or evaporation, they may be imagining different processes than the terms suggest. This can relate to how the effect of insulation or draughts is imagined. These mental models can inform future energy efficiency communications and educational building literacy programmes. 
[1] European Union, Council of the European Union. (2012) Directive 2012/27/EU of the European Parliament and the Council of $25^{\text {th }}$ October, 2012 on energy efficiency, Retrieved from http://eur-lex.europa.eu/legalcontent/EN/TXT/PDF/?uri=CELEX:52014DC0015\&from=EN

[2] O. Guerra Santin, L. Itard. The effect of energy performance regulations on energy consumption. Energy Efficiency. 5(3) (2012) 269-282. DOI: 10.1007/s12053-012-9147-9

[3] T. Dietz. Narrowing the US energy efficiency gap. PNAS (2010) 107:37. DOI: $10.1073 /$ pnas. 1010651107.

[4] S. Royston. Dragon-breath and snow-melt: Know-how, experience and heat flows in the home. Energy Research and Social Science 2 (2014) 148158 DOI:10.1016/j.erss.2014.04.016

[5] G. Huebner. Domestic energy consumption - What role do comfort, habit and knowledge about the heating system play? Energy and Buildings 66 (2013) 626-636.

[6] K. Revell, N. Stanton. Case studies of mental models in home heat control: Searching for feedback, valve, timer and switch theories. Applied Ergonomics (2014) 45 (2014) 363-378.

[7] M.G. Morgan, B. Fischhoff, A. Bostrom, C. Atman. Risk Communication: A mental models approach. (2002) Cambridge, Cambridge University Press.

[8] D. Norman. The design of everyday things. (2002). New York, Basic Books.

[9] D. Gentner, A. Stevens. Mental Models. (1983). Hillsdale, NJ: Lawrence Erlbaum Associates

[10] W. Kempton. Two theories of home heat control. Cognitive Science 10 (1986) 75-90.

[11] K. Rathouse, B. Young. Market Transformation Programme - Domestic Heating: Use of Controls, (2004). Retrieved June 2016

http://webarchive.nationalarchives.gov.uk/search/?lang=en\&where=text\&quer $\mathrm{y}=$ Domestic + Heating + Controls \&noneW $=\&$ exactW $=$ Rathouse\&format $=a l l \& \mathrm{x}=3$ $1 \& y=12 \&$ search type $=$ category \&site $=$

[12] D. Gentner, D. Gentner. Flowing waters or teeming crowds: Mental models of electricity. In D. Gentner, A. Stevens (Eds). Mental Models. (1983). Hillsdale, NJ: Lawrence Erlbaum Associates. 
[13] L. Gabe-Thomas, I. Walker, B. Verplanken, G. Shaddick. Householders' Mental Models of Domestic Energy Consumption: Using a Sort-And-Cluster Method to Identify Shared Concepts of Appliance Similarity. PLOS One: Tenth Anniversary. (2016). DOI: 10.1371/journal.pone.0158949

[14] A. Bostrom, M. Morgan, B. Fischoff, D. Read. What do people know about global climate change? Mental models in A Bostrom, MG Morgan, B Fischhoff, D Read - Risk Analysis, 1994

[15] A. Bostrom, B. Fischhoff, M. Morgan. Characterizing mental models of hazardous processes: A methodology and an application to radon. Journal of Social Issues 48 (4) (1983) 85-100.

[16] P. Hayes. The naive physics manifesto, in D Michie (Ed) Expert Systems in the Microelectronic Age (1979) Edinburgh University Press

[17] U.S. Department of Energy. Energy Literacy: Essential principles and fundamental concepts for energy education. (2013) Retrieved October 2016 http://energy.gov/eere/education/energy-literacy-essential-principles-andfundamental-concepts-energy-education

[18] N. Boase, M.P. White, C. Redshaw and W. Gaze. Evaluating the mental models approach to developing a risk communication: A scoping review of the evidence. Risk Analysis (2017) DOI: 10.1111/risa.12789

[19] P. Linville, G. Fischer, B Fischhoff. AIDS risk perception and decision biases in In J.B. Pryor \& G.D. Reeder (Eds.). The social psychology of HIV infection (pp. 5-38). Hillsdale, NJ Erlbaum.

[20] K. Janda, M.Topouzi, Telling tales: using stories to remake energy policy. Building Research \& Information (2015) 43:4, 516-533,

DOI:10.1080/09613218.2015.1020217

[21] G. Branco, B. Lachal, P. Gallinelli, W. Weber. Predicted versus observes heat consumption of a low energy multifamily complex in Switzerland based on long-term experimental data. Energy and Buildings 36 (2004) 543-555.

[22] P. De Wilde. The gap between predicted and measured energy performance of buildings: A framework for investigation. Automation in Construction (2014) 41 40-49. DOI : 10.1016/j.autcon.2014.02.009

[22] S. Darby. Coal fires, steel houses and the main in the moon; local experiences of energy transitions. Energy Research and Social Sciences (2017) SI: Narratives and storytelling

[24] S. Darby. Social learning and public policy: lessons from an energyconscious village. Energy Policy (2006) 34 (17). 2929-2940. DOI: doi.org.plymouth.idm.ocic.org/10.1016/j.enpol.2005.04.013 
[25] B. Goodchild, A. Ambrose, A. Maye-Banbury. Storytelling as oral history: revealing the changing experience of home heating in England._Energy Research and Social Sciences (2017) SI: Narratives and storytelling

[26] E. Gosden. Are you using your thermostat wrongly: Five home heating errors pushing up energy bills. (2014, $20^{\text {th }}$ October). The Telegraph. Retrieved from http://www.telegraph.co.uk/finance/personalfinance/energybills/11171016/Are-you-using-your-thermostat-wrongly-Five-home-heatingerrors-pushing-up-energy-bills.html

[27] P. O'Sullivan and P.A. McGeevor. "The effects of occupants on energy use in housing." Energy conservation in the built environment. Proceedings of CIB W67 Third International Symposium. Dublin, Ireland: An Foras Forbartha, (1982). pp. 5.96-5.107.

[28] R. Jones, A. Fuertes, C. Boomsma, S, Pahl. Space heating preferences in UK social housing: A socio-technical household survey combined with building audits. (2016) 127 382-398. DOI:

http://dx.doi.org.plymouth.idm.oclc.org/10.1016/i.enbuild.2016.06.006

[29] S. Attari, M. DeKay, C. Davidson, W. Bruine de Bruin, Public perception of energy consumption and savings. Proceedings of the National Academy of Sciences of USA, (2010) 107 (37). 16054 - 16059

[30] A. Carrico, P. Padgett, M. Vandenberg, J. Gilligan, K. Wallston. Costly myths: An analysis of idling beliefs and behavior in personal motor vehicles. Energy Policy (2009) 37:2881-2888.

[31] G. Huebner, J. Cooper, A. Moon, P. Maras, K. Jones. Barriers towards reducing domestic energy consumption - Findings of a study among social housing tenants. International Journal of Environment and Sustainable Development . (2014) 13 (4) pp. 425-448. DOI:10.1504/IJESD.2014.065011.

[32] F. Bowden, D. Lockton, R. Gheerawo, C. Brass. Drawing energy: exploring the aesthetics of the invisible. (2015) London: Royal College of Art. ISBN 978-1-910642-10-8

[33] D. Lockton, WP3 ,Mental models of HVAC systems 'ethnography sessions at DECC. (2011).

[34] K. Gram-Hanssen. Residential heat comfort practices: understanding users. Building Research \& Information, (2010) 38 (2), 175-186.

[35] Burchell, K., Rettie, R., Roberts, T., (2014). Working together to save energy? Report of the smart communities project. Available at: http://business.kingston.ac.uk/sites/all/themes/kingston_business/charmprojec t/smartcommunities.pdf (Accessed: 09/03/2016). 
[36] M. Nevius, S. Pigg, S. Programmable Thermostats That Go Berserk: Taking a Social Perspective on Space Heating in Wisconsin. Proceedings of the 2000 ACEEE Summer Study on Energy Efficiency in Buildings, (2000) 8.233-238.244.

[37] S. Kesidou, R. Duit, S. Glynn. Conceptual development in physics: Students' understanding of heat. In S. M. Glynn \& R. Duit (Eds.), Learning science in the schools: Research reforming practice (1995). Mahwah, NJ: Erlbaum.

[38] G. Chiou, R. Anderson. A study of undergraduate physics students' understanding of heat conduction based on mental model theory and an ontology-process analysis. Science Education. (2010). 94 (5). 825-854. DOI: $10.1002 /$ sce.20385

[39] H. Chu, D. Treagust, S. Yeo, M. Zadnik. Evaluation of Students' Understanding of Thermal Concepts in Everyday Contexts, International Journal of Science Education, (2012) 34:10, 1509-1534, DOI: 10.1080/09500693.2012.657714.

[40] M. Chi, Slotta, J., N de Leeuw. From things to processes: A theory of conceptual change for learning science concepts. Learning and Instruction. (1994) 4 27-43.

[41] M. Wiser, T. Amin. "Is heat hot?" Inducing conceptual change by integrating every day and scientific perspectives on thermal phenomena. Learning and Instruction, (2001) 11(4), 331 - 355.

[42] T. Kruatong, S. Sung-Ong, P. Singh, A. Jones. Thai high school students' understanding of heat and thermodynamics. Journal of Kasetsart (2006). 27, 321-330.

[43] H. Georgiou, M. Sharma, J. O’Byrne, I. Sefton, B. Mclnnes, B. University students' conceptions about familiar thermodynamic process and the implications for instruction. The Uni-Serve Science 2008 (2008). Conference proceedings: Retrieved June 2016, from http://openjournals.library.usyd.edu.au/index.php/IISME/article/viewFile/6203/ $\underline{6851}$

[44] G. Luera, C. Otto, P. Zitzewitz. Use of the thermal concept evaluation to focus instruction. The Physics Teacher, (2006). 44(3), 162-166.

[45] Energy Savings Trust (2017) Cavity Wall. Accessed 27.01.2017 http://www.energysavingtrust.org.uk/home-insulation/cavity-wall

[46] K. Janda. Buildings don't use energy: people do. Architectural Science Review. (2011) 54(1) 15-22. 
[47] S. Pahl, S.R.J. Sheppard, C. Boomsma \& C. Groves. Perceptions of time in relation to climate change. Wiley Interdisciplinary Reviews (WIREs) Climate Change, (2014) 5, 375-388.

[48] S. Pahl, J. Goodhew, C. Boomsma \& S.R.J. Sheppard. The role of energy visualisation in addressing energy use: Insights from the eViz project. Frontiers in Psychology: Personality and Social Psychology (2016) 7 , 92. DOI: $10.3389 /$ fpsyg.2016.00092

[49] G. Huebner, D. Shipworth, S. Gauthier, C. Witzel, P. Raynham, W. Chan. Saving energy with light? Experimental studies assessing the impact of colour temperature on thermal comfort. Energy Research \& Social Science, (2016) 15, 45-57. (doi:10.1016/j.erss.2016.02.008).

[50] C. Boomsma, J. Goodhew, S. Goodhew, S. Pahl. Improving the visibility of energy use in home heating in England: Thermal images and the role of visual tailoring. Energy Research and Social Science 14 (2016). 111-121.

[51] J. Goodhew, S. Pahl, T. Auburn, S. Goodhew. Making Heat Visible; Promoting energy conservation behaviors through thermal imaging. Environment and Behavior. 47 (2015) 10. 1059- 1088. DOI: $10.1177 / 0013916514546218$

[52] H. Gibson, I.S. Stewart, S. Pahl, and A. Stokes. A mental models' approach to the communication of subsurface hydrology and hazards. Hydrology \& Earth System Sciences. (2016) 20 (5) DOI:10.5194/hess-201737-2016

[53] B. Mallaband, V. Haines and A. Morton. Do intelligent heating controls out-smart ordinary users? BEHAVE 2016 (2016) :

https://dspace.lboro.ac.uk/2134/21759

[54] K.M. Revell and N.A. Stanton. Mind the gap - Deriving a compatible user mental model of the home heating system to encourage sustainable behaviour, Applied Ergonomics (2016) 57:48-61. DOI: 10.1016/j.apergo.2016.03.005

[55] K. M. A. Revell. and N. Stanton. When energy saving advice leads to more, rather than less, consumption. International Journal of Sustainable Energy, (2015) 1-19. DOI: 10.1080/14786451.2014.999071

[56] T. Auburn \& R. Barnes. 'Producing place: A neo-Schutzian perspective on the "psychology of place" Journal of Environmental Psychology 26, (2006)

(1) 38-50. DOI: 10.1016/j.envp.2006.03.002

[57] Department for Business, Energy and Industrial Strategy. Energy consumption in the UK (2016). Accessed 19.05.2017 
https://www.gov.uk/government/uploads/system/uploads/attachment_data/file/ 573269/ECUK_November_2016.pdf 
Table 1: Questions to participants, with rationale for each question.

\section{Question}

\section{Thermostat Control}

1. Scenario question: On a cold day when you get home and the house is cold, should you turn the heating up extra high to warm the building more quickly or not?

2. Can you explain how you think of a thermostat working?

2a Supplementary question: How do you imagine the thermostat affects the central heating?
Rationale

Capture mental models of the operation of heating controls. What it is they control and how.

Predicted to affect participant decisions about thermostat set points and frequency of change, behaviour that might lead to overshooting the desired temperature and the energy waste consequences of this.

To assess participants mental models against previous literature. Valve or Feedback, Timer or Switch models described by (Kempton, 1986; Revell, 2014; Norman, 2002)

\section{Heat Flow and Movement}

3. Tell me where heat goes to when the source of heat is switched off?

4. How do you imagine insulation working?

5. Tell me about the way you imagine heat moving around your home?

(if you find it easier, you can draw your explanation on the paper provided)?
Related to decisions regarding length of time heating system is on, opportunities to reduce heating time, decisions to insulate, heat exchange, heat storage and transmission, $U$ values, rate of heating.

To capture models of heat transmission, heat transference. 
Table 2: Mental Models of the relationship between the thermostat set point and the rate of heating a home.

\begin{tabular}{|c|c|c|}
\hline Feedback Model $(n=12)$ & Valve Model $(n=4)$ & 'Fuzzy’ Models $(n=9)$ \\
\hline $\begin{array}{l}\text { Participant 23: So when it gets to } \\
\text { the temperature, so like if it was } 20 \\
\text { degrees in the room then it would } \\
\text { turn off until it gets to below } 20 \\
\text { degrees again and then it would } \\
\text { come back on again. } \\
\text { And } \\
\text { Participant } 5: \text { The thermostat } \\
\text { sends a signal to the boiler which } \\
\text { means that the boiler will not cut } \\
\text { out when it reaches } 15, \text { it will cut } \\
\text { out when it reaches } 20 \text {. }\end{array}$ & $\begin{array}{l}\text { Interviewer: So if the room is cold, say it's } \\
\text { down below } 12 \text { degrees and you want it higher } \\
\text { and you want it about 20, you turn it up to } 20 \text {, } \\
\text { what would be happening? } \\
\text { Participant 15: Well you imagine more gas } \\
\text { being used to heat up the radiators, to heat up } \\
\text { the water in the radiators. } \\
\text { And } \\
\text { Participant 16: I suppose when you turn it, } \\
\text { it...kind of...I don't know, I suppose it's a bit like } \\
\text { a cooker you turn it up the more gas sort of } \\
\text { comes out. Maybe there's a valve like a valve } \\
\text { that opens so it lets more heat through maybe. } \\
\text { And } \\
\text { Participant 17: I think rationally I presumed it } \\
\text { linked back to the boiler and drives how hard } \\
\text { the boiler's working. }\end{array}$ & $\begin{array}{l}\text { I: I wondered if you know how a thermostat works. How it effects the system } \\
\text { beyond it? Do you know how it works? } \\
\text { P13: No I don't no. } \\
\text { I: How do you imagine it working? } \\
\text { P13: I guess they're linked to the radiators in a way. A radiator's filled with } \\
\text { water is that right? So when you turn the thermostat up I guess it heats the } \\
\text { water in the radiator to that temperature but I'm not sure if that's right, that's } \\
\text { what I would have thought, that's a guess. } \\
\text { I: And the thermostat, how does that control it then? How does that affect } \\
\text { the water? } \\
\text { P13: Do you mean how are they linked? I don't know, I don't know. } \\
\text { I: When you turn on the one you've got does it do anything or does it...? } \\
\text { P13: When you turn it? } \\
\text { I: Yeah. When you turn it what are you imagining is happening when you } \\
\text { make the turn as it were? } \\
\text { P13: I don't know. I've never really thought of it. It just happens and you } \\
\text { don't really think about it. I'm not sure to be honest. } \\
\text { And } \\
\text { I'm just wondering if you could explain how the thermoset works. } \\
\text { P20: (pause) well I would imagine that when you set it like that, that's the } \\
\text { target temperature that it is kind of working towards and once it reaches the } \\
\text { temperature it maintains it so it's working hard to reach that point. } \\
\text { I: Yhy, yhy. Okay and do you know how it switches on and off? Cos you have } \\
\text { this, when it gets to certain temperature it just switches off? } \\
\text { P20: If it's set on a timer it wouldn't switch off it would maintain. } \\
\text { I: So do you know how it is sort of switching on and off? How it is sort of } \\
\text { P20: I can hear it in the boiler. Umm, sometimes I hear it firing up but other } \\
\text { times it's more of a click click click kind of that noise. } \\
\text { I: Yeah, yeah. And you don't know how that with the digital display and } \\
\text { numbers in is effecting what the boiler does? } \\
\text { P20: No, I never given it any thought.. I just know the basics. It does what is } \\
\text { said on the tin. }\end{array}$ \\
\hline
\end{tabular}


Table 3: Mental Models of the rate of heat in a building.

\begin{tabular}{|c|c|c|c|}
\hline $\begin{array}{l}\text { Constant Rate of Heat } \\
\text { Model } \\
(n=11)\end{array}$ & $\begin{array}{l}\text { Higher Temperature } \\
\text { - Warmer Faster } \\
\text { model }(n=9)\end{array}$ & $\begin{array}{l}\text { Psychological } \\
\text { Effect Model }(n=1)\end{array}$ & $\begin{array}{l}\text { Slowly, Slowly Model (n } \\
=1)\end{array}$ \\
\hline $\begin{array}{l}\text { Participant 1: No (I would not turn the } \\
\text { temperature on the thermostat up), it } \\
\text { just heats to that temperature, all you } \\
\text { are doing is getting it to a hotter } \\
\text { temperature. } \\
\text { AND } \\
\text { Participant 2: No it still takes } 5 \text { minutes } \\
\text { to get to } 60 \text { and } 5.5 \text { to get to } 70 . \\
\text { AND } \\
\text { Participant } 5: \text { No, I would just switch it } \\
\text { up a little bit. I would switch it to the } \\
\text { temperature that I want it to be and not } \\
\text { high. It is going to get time to...I am } \\
\text { not sure how much gas is being } \\
\text { burned and how that relates to the } \\
\text { temperature. I suppose there is a } \\
\text { thermostat that can control the } \\
\text { temperature in the pipes. I have not } \\
\text { read the instructions in detail. I do not } \\
\text { want it to get ultra-hot, I only want it to } \\
\text { get a certain temperature. I will wait } \\
\text { and I will put a cardigan on. }\end{array}$ & $\begin{array}{l}\text { Participant 7: Em. I would, I } \\
\text { would. I would turn it up but } \\
\text { with hindsight it probably } \\
\text { would not make it get hotter } \\
\text { any faster. I presume that } \\
\text { the boiler would be working } \\
\text { harder to heat water hotter } \\
\text { so that the radiators were } \\
\text { putting it out faster. } \\
\text { AND } \\
\text { Participant 18: Yeah, I would } \\
\text { do. } \\
\text { I (turn up the temperature set } \\
\text { point) ........ Umm (pause) I } \\
\text { just imagine it "chucking it } \\
\text { out" a lot quicker which is } \\
\text { probably contradictive } \\
\text { because then what happens, } \\
\text { you will get too hot and then } \\
\text { you need to turn it back } \\
\text { down and then you are } \\
\text { dealing with it, with being too } \\
\text { hot so you should probably } \\
\text { turn it up a couple of } \\
\text { degrees, but I would } \\
\text { probably if it is really cold } \\
\text { when I got back, I would turn } \\
\text { it up. Probably higher than I } \\
\text { would want it and then turn it } \\
\text { back down. Once it's } \\
\text { reached the point that it was } \\
\text { hot. }\end{array}$ & $\begin{array}{l}\text { Participant 3: If I was really } \\
\text { cold and I had children with } \\
\text { me or something like that, } \\
\text { then yes........probably. } \\
\text { I: And how do you think } \\
\text { that is effective. } \\
\text { Participant 3: I would } \\
\text { imagine it would take quite } \\
\text { a while, but I think it's } \\
\text { probably psychological } \\
\text { more than anything else. } \\
\text { I: So that if you turn it up, } \\
\text { what is the psychological } \\
\text { bit? } \\
\text { Participant } 3: \\
\text { Mmm............. I can't } \\
\text { give you an answer for } \\
\text { that. No, no, it probably } \\
\text { does work. Not } \\
\text { psychologically. In my } \\
\text { house, the radiators would } \\
\text { actually get hotter } \\
\text { somehow. }\end{array}$ & $\begin{array}{l}\text { Participant 4: I would have put it on } \\
\text { lower so that it would build up slower. } \\
\text { I don't know why... just that it would } \\
\text { build up and last longer. Yes, rather } \\
\text { than put it on high? Put it on lower. I } \\
\text { know it would not get warm so fast but } \\
\text { I would imagine that everything would } \\
\text { slowly warm up and that would be } \\
\text { better to do than put it on really hot } \\
\text { and everything was phew, really hot. I } \\
\text { would feel it would last longer then as } \\
\text { well. It would warm up slower but then } \\
\text { you'd have that heat for, you could } \\
\text { have it on longer. } \\
\text { Participant } 4 \text { : With the fires that we } \\
\text { have got. When you do put it on high. } \\
\text { When you do put it on high it goes off } \\
\text { more often so it cuts itself out. And } \\
\text { when you have it on lower it stays at } \\
\text { that temperature consistently whereas } \\
\text { when you put it on high it would stay } \\
\text { on for a few minutes and then it would } \\
\text { go cold again and then it would keep } \\
\text { going on and off like that and you } \\
\text { think, oh I feel cold, when you have it } \\
\text { on } 15 \text { or } 20 \text { its going to stay at that } \\
\text { heat and not keep switching itself on } \\
\text { and off. That's what I tend to find. } \\
\text { With central heating, they go around } \\
\text { on different radiators don't they and } \\
\text { one will warm up and that will get to a } \\
\text { certain temperature get to the certain } \\
\text { temperature and cut out. }\end{array}$ \\
\hline
\end{tabular}


Table 4: Mental Models of Insulation

\section{The Bouncing Model $(n=4)$}

P17: I suppose any insulation be it in a loft, the stuff that they lay down in those spaces, or in cavity walls I suppose, have insulation in. It's just about bouncing the heat back in. It can't get out to the cold air to be dispersed, in the same way that double glazing is a form of insulation because there's another barrier before it reaches the outside, uncontained world. It's that simple. In the same way clothes keep body heat in, the more clothes and thicker clothes, and thick

wool clothes keep heat in better than a cotton shirt. don't see any difference really in the home and heating the home, body heat's the same thing.

\section{Convection/Conduction Model $(\mathrm{n}=1)$}

P15: Well. it's to do with whether it's a good or a bad conductor of heat. So you would want something that would hold...stop the heat from leaving the building so something that was a bad conductor I guess. Something like fibreglass or if you were using insulating tape something that would just not transfer the heat easily, readily.

\section{Wetsuit Analogy $(\mathrm{n}=1)$}

P19: Um, but I think some of the wall -- the walls, if they have to have holes in, you know, it can't be completely -- the wall can't -- -- be completely -- so that needs a bit room for -- I don't know why, to expand or maybe to keep it like -- maybe it's like a wetsuit, Because a wetsuit works -- but wetsuit works -- Um, you have a layer of water right next to your body. Your body temperature heats that water so it stays at your temperature and it kind of acts as a barrier against that ---- cold water. Because if you think about it if you're in the sea, that's a lot quantity of cold waters. That's the initial cold and then it warms so fast. 
Table 5: Mental Models of Heat Movement

\begin{tabular}{|c|c|c|}
\hline $\begin{array}{l}\text { Heat rises model } \\
(n=11)\end{array}$ & $\begin{array}{l}\text { Particle movement } \\
\text { model } \\
(n=4)\end{array}$ & $\begin{array}{l}\text { Geography Class } \\
\text { Analogy }(n=2)\end{array}$ \\
\hline $\begin{array}{l}\text { P4: the heat rises upwards, } \\
\text { so it doesn't kind of chuck it } \\
\text { out at you. I imagine it rises } \\
\text { right up in the air and then } \\
\text { gradually fills up the room } \\
\text { going back down again. }\end{array}$ & $\begin{array}{l}P 3: \text { I think it warms the air and the } \\
\text { little microbes whizz round at a } \\
\text { rapid rate and heat you up that } \\
\text { way. }\end{array}$ & $\begin{array}{l}\text { P14: I suppose maybe t's } \\
\text { like the whole...sort of like } \\
\text { rain system, you know sort of } \\
\text { hot air rises, cools down, } \\
\text { turns into rain, comes straight } \\
\text { down again because it's cold. }\end{array}$ \\
\hline$A N D$ & & AND \\
\hline $\begin{array}{l}P 7: \text { I guess the way heat } \\
\text { works, it goes up and } \\
\text { circulates and moves } \\
\text { around and comes out from } \\
\text { the radiator. I presume that } \\
\text { most of it goes up and } \\
\text { circulates up around the } \\
\text { room. That's what I } \\
\text { presume and that's what I } \\
\text { hope. }\end{array}$ & & $\begin{array}{l}\text { P3: Geography days, } \\
\text { offshore drift. Air goes up } \\
\text { and sea comes up, offshore } \\
\text { breeze in the morning, night } \\
\text { comes the other way. }\end{array}$ \\
\hline
\end{tabular}




\section{APPENDIX 1}

Participant's description of their own heating system

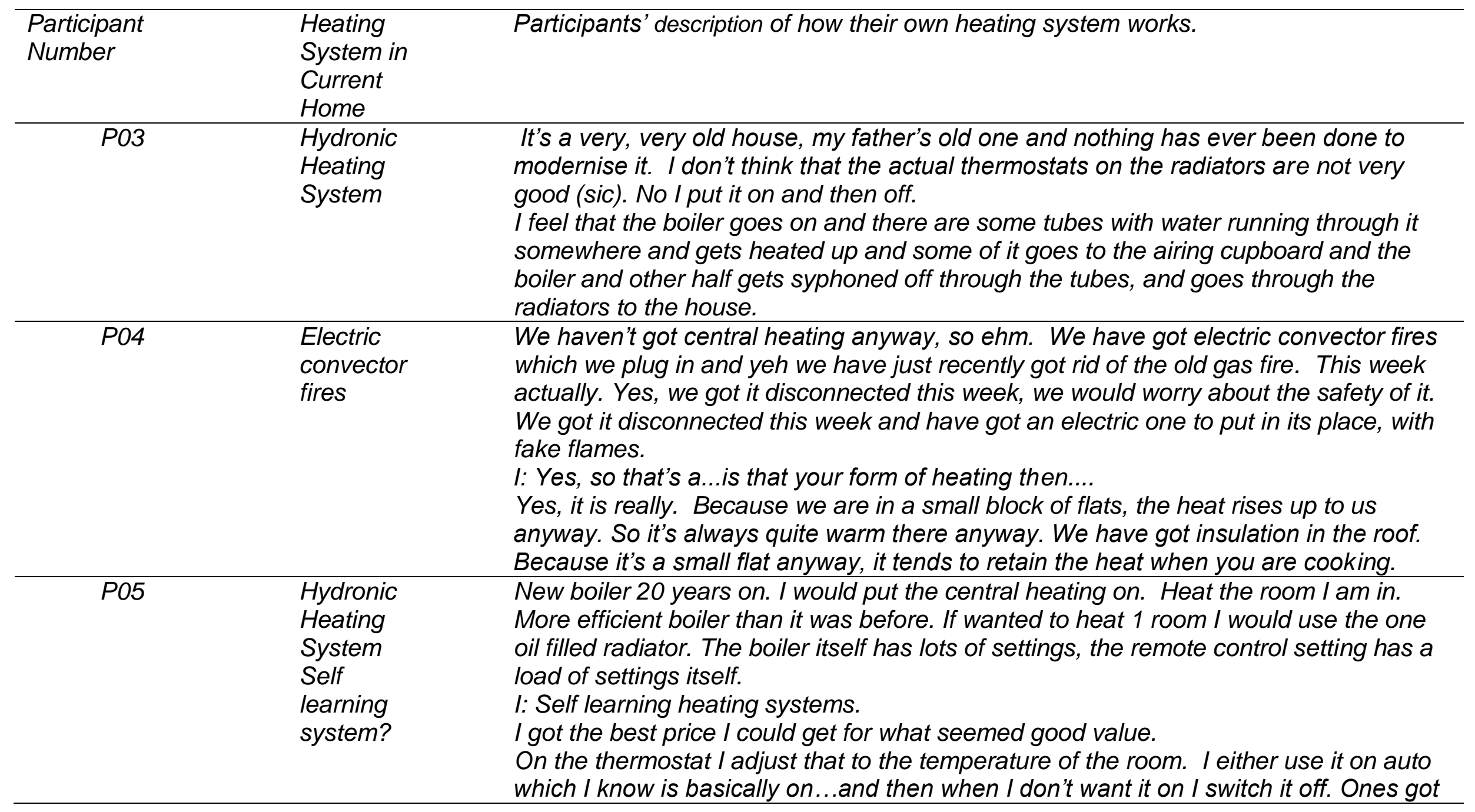


a sun and a moon and I am not sure what they entail, they are versions of on ...not having read the brochure.

P06 Hydronic The (heating has a) switch on the left hand side, I just dash up to the bathroom, just Heating turn it on the left hand side. Ahm. And that does the hot water and the heating.

System $\quad$ I: Would you switch it off again manually.

Yes, I do. I would switch it off at night. Unless I wanted it to be on and then there are four settings, it says once, twice, it would go on and off at night if I wanted it to do so, but I don't. So I just switch it off and I go to bed.

P09 Hydronic I switch it all on and, I don't know, I have to adjust the dial. I often do actually adjust Heating the dial within the boiler. I've got a timer, I've got a dial to adjust it so the radiator heat System, $\quad$ can go up and down but then I have a thermostat as well so I kind of play with them both. So that gets adjusted quite a bit. I don't know how I keep warm! It just turns on and it kind of works. It's just a matter of adjusting things to get it right and get it comfortable.

\begin{tabular}{|c|c|c|}
\hline P10 & $\begin{array}{l}\text { Hydronic } \\
\text { Heating } \\
\text { System }\end{array}$ & $\begin{array}{l}\text { We've got a little thermometer thing. I turn the thermostat, which is broken at the } \\
\text { moment so we have to have it really high to have the heating on at all which is } \\
\text { really...it really drives me up the wall. The heat won't kick in unless it's up above } 20 . \\
\text { So if I was feeling cold and I looked at the temperature thing (on the fridge magnet) } \\
\text { and the temperature was reasonably okay I would think right I won't turn the heating } \\
\text { up I'll stand by the cooker for a bit or just go for a walk, whereas if it's say } 17 \text { or } 19 \text { or } \\
\text { something I'd think oh fair enough they're right it is cold }\end{array}$ \\
\hline P14 & $\begin{array}{l}\text { Hydronic } \\
\text { Heating } \\
\text { System }\end{array}$ & $\begin{array}{l}\text { Yeah we've had a sort of boiler system, both houses had similar things, you just } \\
\text { push...it had a clock face and you could push in the times that you wanted to } \\
\text { automatically have it on. So l've always understood the boiler as being sort of just the } \\
\text { radiators and sort of contributes to the water and obviously then you've got a separate } \\
\text { bill for the electricity which is just TV and power source for other things. }\end{array}$ \\
\hline$P 17$ & $\begin{array}{l}\text { Hydronic } \\
\text { Heating } \\
\text { System }\end{array}$ & $\begin{array}{l}\text { It's radiators in every room. It's a ground floor flat. There's a boiler just at the back in } \\
\text { a little boiler cupboard, airing cupboard. } \\
\text { I don't know about the thermostat because I control it on the radiators. I don't think } \\
\text { there is one of those thermostat things anywhere in the flat it's literally just push the } \\
\text { button a couple of times and it turns on, push it a couple of times and it turns off; it's a } \\
\text { reasonably old boiler I think, we need to service it at the moment actually. }\end{array}$ \\
\hline
\end{tabular}




\begin{tabular}{|c|c|c|}
\hline P18 & Oil fired & $\begin{array}{l}\text { I think we have our heating um, our oil fire, boiler/radiators, on a timer so hopefully } \\
\text { that would be adjusted in a manner that um, suites the weather pattern. And the boiler } \\
\text { is -- Oil fire, yes, domestic oil. So you have a tank outside? Yes, yes. And it's timed to } \\
\text { come on -- Yes, morning and evening; yes, just for a short period of time. Um, okay. } \\
\text { And that fires the radiators Does that have a thermostat or a sort of setting on it, that's } \\
\text { probably a bit -- It does, yes, a thermostat and it's set at a certain -- I think at } 140 \\
\text { degrees on the dial on the boiler itself. }\end{array}$ \\
\hline$P 20$ & $\begin{array}{l}\text { Hydronic } \\
\text { Heating } \\
\text { System }\end{array}$ & $\begin{array}{l}\text { Yeah, we've got a boiler and we've got radiators, we've got a living room, dining room } \\
\text {-- we've got radiators in all the bedrooms and in the hallways as well. } \\
\text { So the system was new in 2007. We've got it timed that it comes on so when I get in } \\
\text { from work it's a certain temperature and it's nice and then it sort of clocks back down } \\
\text { to a -- I don't know whether it's } 16 \text { or } 17 \text { or something. It goes back down again and } \\
\text { then in the middle of the night, about four it comes back on -- this is winter months } \\
\text { obviously -- so it comes back on for a couple of hours so it's warm when we're getting } \\
\text { up in the morning and then goes back down again. So it's kind of timed to do -- to kick } \\
\text { in when we need it. And we can override it so if it's particularly cold, we just stick it to } \\
\text { manual and turn it up. }\end{array}$ \\
\hline$P 21$ & $\begin{array}{l}\text { Hydronic } \\
\text { Heating } \\
\text { System }\end{array}$ & $\begin{array}{l}\text { There is a boiler -- and a thermostat on the wall and radiators? There's a timer with a } \\
\text { dial and it has notches in -- it has a } 24 \text { hour thing, but in few minute increments so } \\
\text { that's what we used to do, but in the time that we weren't going to be in the house, for } \\
\text { example if we were going to university from nine until five or six, it would be off. The } \\
\text { only time we would use the gas is for cooking and eating. }\end{array}$ \\
\hline$P 25$ & $\begin{array}{l}\text { Hydronic } \\
\text { Heating } \\
\text { System }\end{array}$ & $\begin{array}{l}\text { The thermometer, to turn up the heat or down and then, my mum goes turn it up and } \\
\text { then, when it clicks is when it started. }\end{array}$ \\
\hline
\end{tabular}




\section{APPENDIX 2}

\section{Example responses to the question "Where heat goes to when the source is switched off?"}

P1: I view it as it sort of like signals.

I: Right, okay. So that's the sort of the control system?

l: Okay, so that's interesting, so you know how it sends out the mechanism? How the signals are being sends out?

$P: 1$ I have not got a clue. Not got a clue, other than I see the device that I press

P2: I never really thought about it, it just sort of seems to, like if I open a window and it just sort of escapes. Other than that I would not know, it sort of like evaporates.

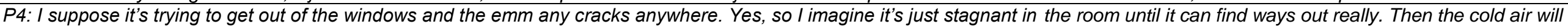

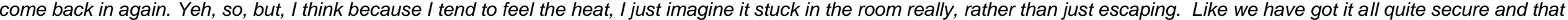
with double glazing.

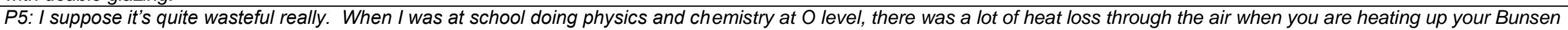
burner. Everything was supposed to balance but when it didn't it was put down to heat loss. I have no idea what they are talking about to be honest.

P16: I don't know, it just gets evaporated into the air I suppose.

I: How do you imagine that happening? So you said evaporated into the air.

P16: I don't know, I suppose when you open a door the sort of heat goes out I don't know.

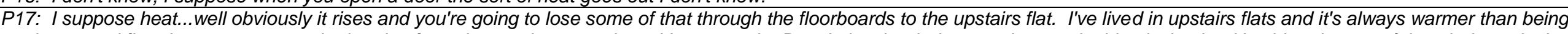

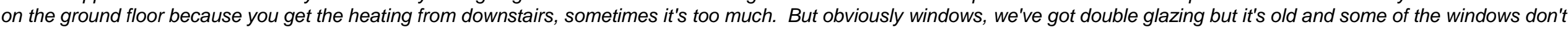

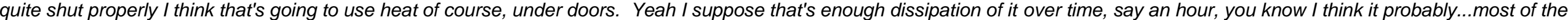
benefit is lost over that sort of time frame I suppose.

P19: I always assumes stones are solid ---- and nothing can get -- through them. Um, but that, yeah, so I think about maybe like it goes through like cracks and stuff

I: And then what?

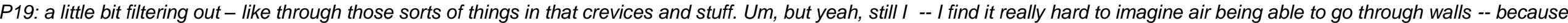

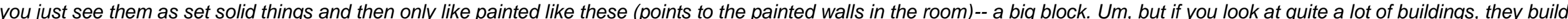
them like of breeze blocks and stuff, there is quite a lot of air in them. So it does make sense that they can go through.

P19: I just really find it hard to imagine that anything can go through walls.

I: Yeah. Yeah. And do you -- you think -- can you imagine how much goes through the window if you've gotten

P: Um, for a single glaze, I reckon it's got to be low so -- it's got to be like $80 \%$ I reckon. I reckon a lot goes through that. Um, so I think even if you can't like double glaze, like my

windows cost -- well cost about five grand just to -- -- double glaze them but just having that therm, I think, probably cuts that quite a lot

I: So do you -- do you have any model or -- and mentioning if -- how they work?

P: Um, well, it's really hard because they're so thin. You think, how could they possibly have -- that -- again, how do they work?

I: So the moment you switch the whole thing off, where does the heat disappear to, or doesn't it, does it just stays there?

P20: I got no clue, I view is as it locked up in the boiler. Haha, I know it's completely not how it is at all but I just view it as locked in this little box that is boiler.

P20: And then it sends signals to everywhere else to turn it on so I just view that as the potential for the heating.

P20: But everything else just being cold until it gets the signal.

P20: I view it as it sort of like signals.

I: Right, okay. So that's the sort of the control system?

I: Okay, so that's interesting, so you know how it sends out the mechanism? How the signals are being sends out?

P20: I have not got a clue. Not got a clue, other than I see the device that I press.

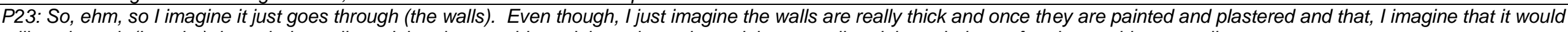
still go through (Laughs) through the walls and then just outside and through cracks and that as well and through the roof and everything as well. 
Figure 1

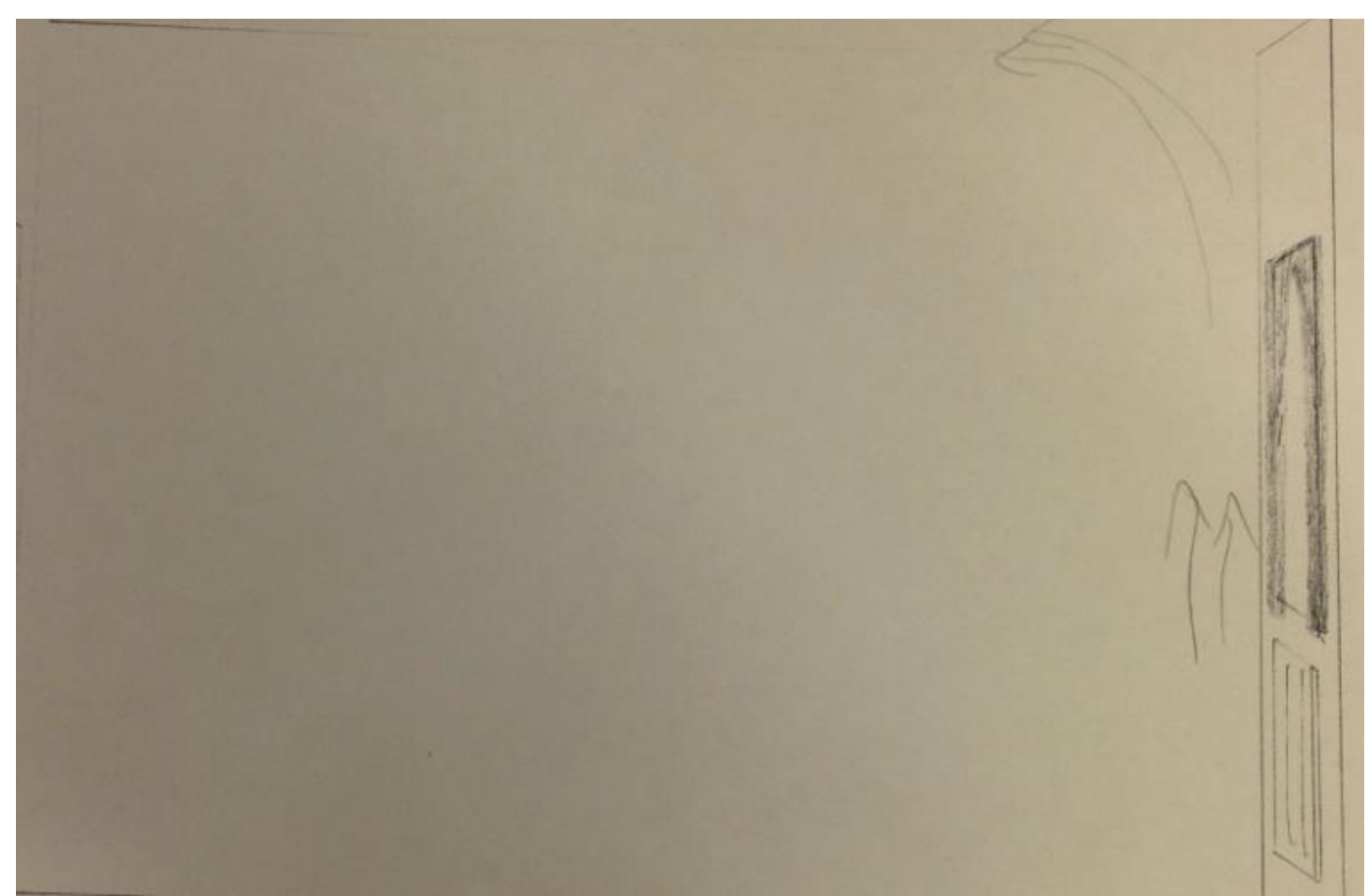

Fig 1 Sketch of heat rises model of heat flow with arrows representing hot air rising from the radiator on the wall, under the window (Participant 1) 
Figure 2

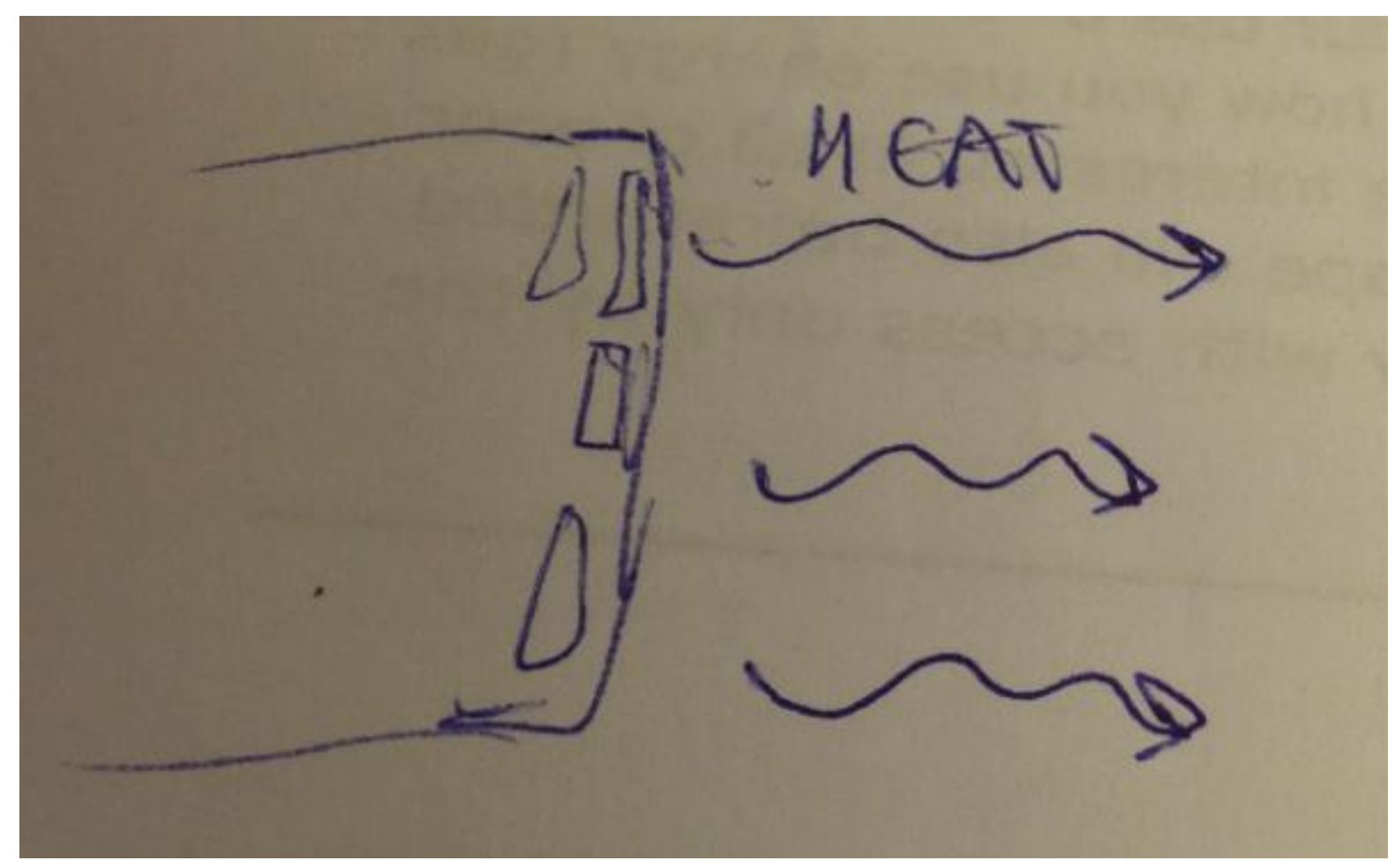

Fig 2 Sketch of heat spreading outwards horizontally from a radiator in to a room (Participant 23) 
